\title{
As estruturas da vida cotidiana e a terapia ocupacional: tensionando limites e possibilidades no/do ${ }^{\mathbf{1}}$ exercício profissional
}

\section{The structures of everyday life and occupational therapy: tensioning limits and possibilities inlof the professional practice}

\author{
Waldez Cavalcante Bezerra ${ }^{a}$ (D), Roseli Esquerdo Lopes ${ }^{\mathrm{b}}$ (D), Ana Carolina de Souza Basso ${ }^{\mathrm{c}}$ \\ ${ }^{a}$ Universidade Estadual de Ciências da Saúde de Alagoas - UNCISAL, Maceió, AL, Brasil. \\ ' Universidade Federal de São Carlos - UFSCar, São Carlos, SP, Brasil. \\ 'Instituto Federal de Educação, Ciência e Tecnologia do Rio de Janeiro - IFRJ, Rio de Janeiro, RJ, Brasil.
}

Como citar: Bezerra, W. C., Lopes, R. E., \& Basso, A. C. S. (2022). As estruturas da vida cotidiana e a terapia ocupacional: tensionando limites e possibilidades no/do exercício profissional. Cadernos Brasileiros de Terapia Ocupacional, 30, e3031. https://doi.org/10.1590/2526-8910.ctoEN22983031

\begin{abstract}
$\underline{\text { Resumo }}$
Este ensaio objetiva refletir sobre o exercício profissional de terapeutas ocupacionais tomando como referencial teórico a concepção de cotidiano com base em Agnes Heller. Na terapia ocupacional, a discussão sobre cotidiano e vida cotidiana revela uma ênfase no seu uso como uma chave de leitura e de intervenção para pensar a vida das pessoas, grupos ou populações destinatárias das açóes profissionais; assim, o foco tem sido sempre o cotidiano do outro. Propomos, neste artigo, um deslocamento reflexivo e problematizamos o cotidiano do profissional em si, entendendo que os limites e possibilidades no/do trabalho são tensionados no espaço da vida cotidiana em que o exercício profissional acontece e é atravessado pelas estruturas da cotidianidade. Discutimos o próprio cotidiano como locus de resistência à alienação e à possibilidade de suspensôes temporárias da cotidianidade por meio de um trabalho crítico, capaz de articular as dimensóes técnica, ética e política do exercício profissional, de transitar entre as esferas individual e coletiva na leitura e intervenção sobre as demandas profissionais, de superar a dicotomia teoria e prática e, assim, reafirmar o compromisso com a transformação da sociedade, em que lutas por redistribuição e reconhecimento produzam justiça e participação social.
\end{abstract}

Palavras-chave: Terapia Ocupacional/Tendências, Atividades Cotidianas, Prática Profissional.

\footnotetext{
${ }^{1}$ Neste texto, escolhemos o uso da combinação "no/do" para nos referirmos a duas coisas que acontecem ao mesmo tempo: compreendemos que "no" se refere aos processos e contextos de trabalho, enquanto "do" remete à finalidade do trabalho como um todo, sendo, portanto, duas dimensóes constitutivas e inseparáveis do exercício profissional.
} 


\begin{abstract}
$\underline{\text { Abstract }}$
This essay aims to reflect on the professional practice of occupational therapists taking as a theoretical reference the conception of everyday life by Agnes Heller. In occupational therapy, the discussion about everyday life and everyday life reveals an emphasis on its use as a key to reading and intervention to think about the lives of people, groups or populations that are recipients of professional actions; thus, the focus has always been the daily life of the other. We propose, in this article, a reflexive shift and we problematize the daily life of the professional themself, understanding that the limits and possibilities in/of work are tensioned in the space of everyday life in which professional practice takes place and is crossed by the structures of everyday life. We discuss daily life itself as a locus of resistance to alienation and the possibility of temporary suspensions of daily life through critical work, capable of articulating the technical, ethical and political dimensions of professional practice, of moving between the individual and collective spheres in reading and intervention on professional demands, to overcome the theory and practice dichotomy and, thus, reaffirm the commitment to the transformation of society, in which struggles for redistribution and recognition produce justice and social participation.
\end{abstract}

Keywords: Occupational Therapy/Trends, Activities of Daily Living, Professional Practice.

\title{
Introduçáo
}

A homogeneização em direção ao humano-genérico, a completa suspensão do particular-individual, a transformaçâo em "homem inteiramente", é algo totalmente excepcional na maioria dos seres humanos (Agnes Heller, $\mathrm{O}$ cotidiano e a história, 2016, p. 50).

A discussão sobre cotidiano e vida cotidiana tem despertado o interesse de terapeutas ocupacionais brasileiros nas últimas décadas, por meio de diferentes enfoques: o cotidiano como conceito enquanto posição teórica para interpretar a realidade; como conceito para refletir como os processos de adoecimento transformam a vida cotidiana dos sujeitos; como conceito para embasar a análise da vida cotidiana; e como um conceito que embasa a prática (Galheigo, 2003; Salles \& Matsukura, 2015).

A incorporação do conceito na profissão esteve atrelada à crítica ao que se definia como algo suficiente e bastante específico para informar à prática terapêutico-ocupacional as "atividades de vida diária", expressão predominante sobre as ações profissionais, e, consequentemente, à busca de outros referenciais que permitissem pensar, crítica e contextualizadamente, a vida que se desenrola no dia a dia, a vida comum das pessoas. Ainda na década de 1980, Francisco (2001) defendeu o cotidiano como uma construção sócio-histórica que carrega a concretude da vida em suas múltiplas manifestaçóes, resultante das determinações históricas, econômicas, políticas e culturais. Na década de 1990, o cotidiano é tomado na terapia ocupacional como um eixo articulador daquilo que Galheigo et al. (2018) denominaram de práticas emancipatórias em distintos campos da atuação profissional. Para Galheigo (2020, p. 7-8), aqueles que se voltam para os estudos do cotidiano se deslocam para: 
[...] as cenas do dia a dia [que] servem de testemunho de um espaço-tempo moldado pela cultura, pelas histórias de vida e pelas relaçóes sociais. Por meio do cotidiano é possível acessar a experiência, o real, o imaginário, a memória, os sonhos, os sentimentos, as necessidades e os afetos [...] de sujeitos e coletivos.

Tais deslocamentos, em dimensóes teóricas e práticas:

[...] apresentam as camadas duras da repetição e do sofrimento no dia a dia; mostram a delicadeza dos afetos e o encantamento de pequenos gestos e fazeres; visibilizam a diferença, a discriminação, os preconceitos e as injustiças; e oferecem testemunho das possibilidades de criação, reinvenção, cooperação e transformação de si e do mundo (Galheigo, 2020, p. 8).

As produções que articulam o conceito de cotidiano com a terapia ocupacional revelam uma ênfase no seu uso como uma chave de leitura e de intervenção para pensar a vida das pessoas, grupos ou populaçóes destinatárias das açóes profissionais, sempre focando o cotidiano do outro. Contudo, nossos questionamentos recaem sobre o cotidiano do profissional em si, na sua realizaçáo, entendendo que os limites e possibilidades do trabalho são tensionados no espaço da vida cotidiana em que o exercício profissional acontece e é atravessado pelas estruturas da cotidianidade. As estruturas que determinam a cotidianidade, como discutido adiante, expressam-se também na organização das políticas sociais e nas instituiçôes que mediam a inserção profissional no mercado de trabalho.

Compreendemos que. ao exercer a sua atividade profissional intervindo no cotidiano das pessoas, terapeutas ocupacionais estão vivenciando, como seres sociais, uma das atividades e dimensóes do seu cotidiano: o trabalho. Desse modo, o exercício profissional, assim como qualquer outra atividade inserida na cotidianidade, está sujeito às alienaçóes típicas da vida cotidiana da sociedade capitalista. Para Heller (1987), o fenômeno da alienação se expressa enquanto uma incapacidade do indivíduo de superar a naturalização da vida social nos planos do pensamento e da açáo, impedindo-o de realizar uma leitura crítica dos fenômenos e de agir criticamente sobre a sua realidade.

Considerando tais premissas, este ensaio reflete sobre o exercício profissional de terapeutas ocupacionais tomando como referencial teórico a concepção de cotidiano baseada em Agnes Heller (2016), uma vez que as determinaçóes históricas e concretas da prática profissional se colocam e são recolocadas pelas estruturas da vida da cotidiana, fundadas no modo de produção capitalista. Buscamos discutir, dialeticamente, o próprio cotidiano como locus de resistência à alienação e de criação de possibilidades de um trabalho profissional crítico, ético e político.

\section{O Cotidiano e Suas Estruturas: a Suspensáo da Cotidianidade e a Elevaçáo ao Humano-Genérico}

"A vida cotidiana é a vida de todo [ser humano] 2". É com essa frase que Agnes Heller começa seu capítulo sobre a estrutura da vida cotidiana em seu livro $O$ cotidiano e a história

\footnotetext{
${ }^{2}$ No livro, Heller usa o termo homem partindo da sua concepção filosófica como gênero humano, debruçando-se sobre a humanizaçáo do homem no decorrer do processo histórico, opondo-se a uma perspectiva de homem que se humaniza para cumprir os ditames da natureza (Patto, 1993). Na atualidade, esse termo se mostra em descompasso com as construçóes linguísticas que fazem frente à naturalização do masculino como síntese dos gêneros. Optamos pela expressão ser humano para falar do gênero humano.
} 
(Heller, 2016, p. 35). Para ela, ninguém está fora da cotidianidade, sendo que ninguém consegue se desligar dela e se identificar com sua atividade humano-genérica, por todo o tempo; portanto, ninguém conseguiria se desligar da cotidianidade inteiramente. Pontuase que atividade humano-genérica é aquela que conecta o indivíduo particular ao gênero humano e cuja existência e conteúdo podem ser “[...] úteis para expressar e transmitir a substância humana" (Heller, 2016, p. 40).

O cotidiano é essa vida de todos os dias e de todas as pessoas, composta pelos gestos, relaçóes e atividades rotineiras; pelo espaço do banal, do privado, das relaçóes sociais, pela alienação, mas, igualmente, pelo espaço de resistência e possibilidade de transformação social (Carvalho, 2011).

Heller (2016) aponta que existem características em torno das quais a vida cotidiana se estrutura; entre elas, podemos citar que: ela é heterogênea, hierárquica, única e irrepetível, espontânea e pragmática.

A vida cotidiana é heterogênea em seu conteúdo e hierárquica em relação à importância que as atividades têm na vida das pessoas. Essa hierarquia não é imutável, modificando-se "[...] em função das diferentes estruturas econômico-sociais" (Heller, 2016, p. 36). As pessoas têm seus trabalhos, suas vidas privada e pública, seus lazeres; a diversidade de atividades, assim como sua importância, é o que caracteriza essa heterogeneidade e hierarquia.

Para Heller, existiria um pragmatismo e uma economicidade na vida cotidiana. Diante da heterogeneidade de coisas que fazemos em nosso dia a dia, há a necessidade de uma articulação imediata entre o pensar e o agir, o que demanda pragmatismo nas decisóes e açôes, com poucas possibilidades de reflexão crítica, levando-nos a um economicismo no fazer cotidiano; afinal, "[...] na cotidianidade, não é possível concentrar todas as energias em cada decisão" (Heller, 2016, p. 46).

Há também uma espontaneidade na vida cotidiana: trata-se de uma tendência de realizarmos nossas atividades sem termos que refletir constantemente sobre todas essas açôes, pois não poderíamos refletir sobre todo o conteúdo de todas as coisas que fazemos na banalidade do cotidiano; se assim fosse, a produção e reprodução da vida em sociedade seria impossível (Heller, 2016).

Com essas características, a realização das atividades da vida cotidiana exige a construção de juízos ultrageneralizadores, que são juízos provisórios confirmados pelas práticas cotidianas ao longo das experiências do sujeito (Heller, 2016, p. 59-60).

Sempre reagimos a situaçóes singulares, respondemos a estímulos singulares e resolvemos problemas singulares. Para podermos reagir, temos que subsumir o singular, do modo mais rápido possível, sob alguma universalidade; temos que organizá-lo em nossa atividade cotidiana [...], temos que resolver o problema. Mas náo temos tempo para examinar todos os aspectos do caso singular [...]. Temos que situá-lo o mais rápido possível sob o ponto de vista da tarefa colocada. E isso só se torna possível graças à ajuda dos vários tipos de ultrageneralização.

No processo de ultrageneralização, recorre-se à analogia e aos precedentes: precisamos utilizar nossas experiências anteriores como balizadoras para nos orientar nas atividades cotidianas. Outra característica da vida cotidiana é a mimese, que se refere à capacidade que temos de aprender, incorporar hábitos e reproduzi-los (Heller, 2016, p. 62). Em síntese: 
[...] não há vida cotidiana sem espontaneidade, pragmatismo, economicismo, analogia, precedentes, juízo provisório, ultrageneralização, mimese [...]. Mas as formas necessárias da estrutura e do pensamento da vida cotidiana não devem se cristalizar em absolutos, [...] têm de deixar ao indivíduo uma margem de movimento e possibilidades de explicitação. [...] Se estas formas se absolutizam, deixando de possibilitar uma margem de movimento, encontramo-nos diante da alienação da vida cotidiana.

Heller (2016, p. 63) afirma que a vida cotidiana é aquela "[...] que mais se presta à alienação" e que o caminho para a suspensão do cotidiano para alcançar a práxis e a transformação da realidade se dá por meio do alcance dos sujeitos à atividade humanogenérica. Existe uma diferença entre atividade propriamente humana e atividade em geral. Vázquez (2007, p. 219) explica que "[...] toda práxis é atividade, mas nem toda atividade é práxis"; essa se caracteriza enquanto atividade humana, constituída pela relação entre pensamento e ação conscientes, com a finalidade de transformar a realidade do mundo natural ou social, para satisfazer as necessidades humanas. Já a atividade em geral pode prescindir dessa articulação entre pensamento e ação, não sendo necessariamente práxis.

Segundo Heller (2016), existe uma indissociabilidade entre o indivíduo e o coletivo, e o indivíduo é sempre, simultaneamente, ser particular e ser genérico. É ser particular na forma como constitui suas necessidades, torna-se consciente destas e as satisfaz, como também imprime a sua marca no mundo. É ser genérico na forma como constitui o mundo e, pela sua existência, expressa e transmite a substância do que é ser humano:

Enquanto indivíduo, portanto, é o [ser humano] um ser genérico, já que é produto e expressão de suas relações sociais, herdeiro e preservador do desenvolvimento humano; mas o representante do humano-genérico não é jamais um [ser humano] sozinho, mas sempre uma integração (tribo, demos, estamento, classe, nação, humanidade) - bem como, frequentemente, várias integraçóes - cuja parte consciente é o [ser humano] e na qual se forma sua "consciência de nós" (Heller, 2016, p. 40).

O humano-genérico se orienta para o "nós" e é baseado nele que suspendemos o cotidiano e alcançamos a práxis. Heller (2016) afirma que a vida cotidiana não é práxis e que é por meio da suspensão da cotidianidade, com atividade humano-genérica consciente, que nos elevamos ao nível da práxis e transformamos a realidade, o que acontece por meio da homogeneização.

A homogeneização diz respeito ao direcionamento de toda nossa atenção para uma única atividade; todavia, não basta para nos suspendermos da cotidianidade e alcançarmos o humano-genérico. Para tanto, além da homogeneizaçáo, precisa acontecer o emprego de "[...] nossa inteira individualidade humana na resoluçáo desta tarefa" (Heller, 2016, p. 49). A homogeneização que pode levar à práxis é aquela que concentra toda atenção em uma tarefa, mas há de ser também aquela na qual "[...] atuou toda nossa inteira individualidade" (Heller, 2016, p. 50). Neste sentido, as condiçôes para a homogeneização são o foco de toda a individualidade em uma atividade, de forma reflexiva e consciente, sem a interferência das estruturas da vida cotidiana, tais quais o pragmatismo, o economicismo, os juízos ultrageneralizadores e a mimese. 
Heller discorre sobre alguns caminhos que possibilitariam a suspensão mais duradoura da cotidianidade na direção do humano-genérico: a arte, a ciência, o exercício profissional revolucionário e a atividade política. Entretanto, essa elevação ao humano-genérico não significa o não retorno à cotidianidade e sua alienação. Mesmo nessas atividades, não ocorre uma separação rígida da vida e do pensamento cotidiano.

Além disso, a autora enfatiza que a vida cotidiana não é necessariamente alienada em função de sua estrutura, mas apenas em determinadas circunstâncias sociais. É possível ao indivíduo, de modo consciente, encontrar na vida cotidiana margens de movimento, noção que se relaciona com o conceito de "condução da vida" de Heller (2016, p. 67). Assim, a condução da vida se refere a uma possibilidade de o indivíduo ordenar, conscientemente, as várias atividades do dia a dia, imprimindo sua personalidade, mesmo enquanto as condiçóes gerais econômicas e sociais ainda favoreçam a alienação. $\mathrm{O}$ conceito remete, portanto, ao rompimento da alienação cotidiana, pois, apesar das limitaçóes postas pela realidade, cria espaço para se fazer escolhas e estabelecer uma relação consciente entre o indivíduo e a sociedade, entre ser particular e ser genérico.

Tomando essas elaboraçôes de Agnes Heller, interessa-nos problematizar o exercício profissional de terapeutas ocupacionais como atividade inserida na cotidianidade e atravessada por suas estruturas, prestando-se às alienaçóes próprias do cotidiano, bem como refletir sobre a possibilidade de, no exercício profissional, realizarem açóes que suspendam o cotidiano, produzindo atividade humano-genérica, tendo como horizonte a transformação da realidade e da vida das pessoas com as quais lidam. Desse modo, questionamos: quais as margens de movimento para a "condução da vida" no exercício profissional de terapeutas ocupacionais, considerando os limites e contradiçóes postos pela realidade social?

\section{O Exercício Profissional de Terapeutas Ocupacionais: da Cotidianidade à Atividade Humano-Genérica}

Com o reconhecimento de um conjunto de necessidades sociais por parte do Estado, fruto da luta de classes no capitalismo, é instaurada uma nova relação entre o Estado e a sociedade civil, na qual as expressóes da questão social passam a ser alvo da ação de políticas sociais. Esse processo deu base concreta para a criação de um mercado de trabalho e profissionalização de diversas práticas sociais, que encontraram nas políticas e serviços sociais seus principais espaços de intervenção profissional e as condições necessárias para a sua reprodução como profissóes na sociabilidade burguesa (Bezerra, 2011).

Desse modo, a origem e expansão de um conjunto de profissóes, aqui denominadas de profissóes do social ${ }^{3}$, apresentam íntima relação com a fase monopólica do capitalismo, tendo sido demandadas e reconhecidas socialmente nesse período. Dentre essas profissóes, inclui-se a terapia ocupacional, como já tratado por Soares (1987), Lopes (1991) e Bezerra (2011).

Dada a importância das atividades profissionais para manutenção e desenvolvimento do capitalismo desde o Século XX, e para a reprodução da vida em uma sociedade desigual, os serviços sociais se expandiram, mudando os contornos da divisão social do trabalho e impulsionando a ampliação das profissões. Ocupando um lugar nessa divisão, terapeutas

${ }^{3}$ Denominamos de profissóes do social o conjunto de profissóes que participam da produção e viabilizaçáo de serviços e direitos sociais (saúde, educação, assistência social, cultura etc.) como resposta às necessidades postas socialmente por indivíduos, grupos e classes sociais em seu processo de reprodução social. 
ocupacionais, com uma atuação voltada para o cotidiano das pessoas, grupos e comunidades, cumprem um importante papel no processo de regulação das relaçóes e reprodução social, operacionalizando políticas e serviços sociais.

No Brasil, a ampliação dos direitos e serviços sociais, consagrados na Constituição de 1988, ocorreu, contraditoriamente, no contexto da crise estrutural do capitalismo, que se expressava mundialmente desde a década de 1970. Logo, já ao final da década de 1980, a efetivação daquilo que foi estabelecido na Constituição encontrou enormes desafios diante do processo de reestruturação do capitalismo (Bezerra, 2011).

Nesse contexto, se, por um lado, a ampliação das políticas e açôes resultou na expansão do mercado de trabalho para terapeutas ocupacionais, por outro, isso se deu no âmbito de mudanças no Estado, via lógica gerencialista (privatização e/ou subfinanciamento de serviços públicos, focalização do acesso, metas de produtividade etc.), atingindo não só os usuários, mas também os trabalhadores. Para Borges (2015), essa lógica de gestão resulta, quase sempre, na perda de qualidade dos serviços e, consequentemente, no rebaixamento dos níveis de atendimento das necessidades que deveriam suprir.

Para Raichelis (2018), como expressão da modernização conservadora no campo das políticas sociais, o gerencialismo introduz modelos de gestão do trabalho e de informação cuja ênfase está na técnica, situação que favorece a alienação cotidiana dos profissionais que não conseguem discernir e reconhecer, nas formas sociais em que se inserem, os conteúdos e os efeitos do seu trabalho. Esse cenário reestrutura o exercício das profissóes do social, colocando em maior evidência os limites da autonomia profissional sob relaçóes de assalariamento, bem como intensificando as determinaçóes alienantes que estruturam o cotidiano desse exercício.

A expansão da racionalidade formal-abstrata no gerenciamento do trabalho nos serviços sociais tem acarretado a rotinização e desqualificação do trabalho profissional, minimizando a importância de suas dimensóes criativa e crítica pelo uso de instrumentos padronizados, que devem ser incorporados. De acordo com Guerra (2016, p. 105), é nessa lógica que a racionalidade formal-abstrata opera:

É formal, por se restringir a formas próprias da padronização atual das políticas sociais e à lógica dos sistemas; é abstrata porque retira das profissóes seus conteúdos concretos, $[\ldots]$ que responde $[\mathrm{m}]$ a um conjunto de demandas socioprofissionais e políticas, fazendo tábula rasa da formação, do universo cultural de cada profissão, dos projetos profissionais e do projeto de sociedade de cada uma.

Observamos, então, na contemporaneidade, um amplo processo de precarização das condiçóes e relaçóes de trabalho, desdobrando-se em formas de trabalho desprotegido, insegurança laboral, baixa remuneração, assédio moral e adoecimento, num processo de precarização geral não só do trabalho, mas também da vida.

É importante destacar que o desenvolvimento histórico das políticas sociais resulta das relaçóes contraditórias advindas da luta de classes. Ao mesmo tempo em que elas se configuram como meio do Estado administrar os conflitos de classes, sem ameaçar a reprodução do sistema ou resolver de fato os problemas que demandaram a sua existência, representam e atendem às demandas da classe trabalhadora por direitos básicos, bem como configuram meios/espaços/serviços para a atuação profissional. 
Apesar do traço conservador da natureza dessas políticas, a depender do momento histórico e político de como essas são concebidas e geridas pelo Estado, é possível notar impactos diferentes em sua operacionalizaçáo, seja para a populaçáo atendida, seja para os trabalhadores que atuam nos serviços sociais; afinal, resultam também da correlação de forças entre capital e trabalho (Lopes, 2016).

Assim, mesmo o Estado gerencial neoliberal pode assumir diferentes feiçóes. No Brasil, a radicalidade das medidas neoliberais após o impeachment da presidenta Dilma Rousseff em 2016 tem deixado explícitas essas distinçóes, uma vez que a roupagem social-liberal ${ }^{4}$ que marcou os governos de Lula e Dilma, mesmo sem romper com os ditames do [neo]liberalismo, permitiu alguns avanços sociais como aumento do Índice de Desenvolvimento Humano (IDH), os investimentos no combate à pobreza, melhora nos índices educacionais, dentre outros. Esse cenário possibilitava maiores margens de movimento para as reivindicações do trabalho das políticas sociais.

O contexto neoliberal de retração de direitos sociais, de precarização do trabalho e da vida em sociedade, em maior ou menor intensidade ao longo das últimas décadas, desenha uma maior diversidade das demandas a serem respondidas por terapeutas ocupacionais, pois tem provocado o aumento das situaçóes de vulnerabilidade da populaçáo. Essa heterogeneidade de demandas, no cotidiano de serviços precarizados, favorece uma leitura superficial e fragmentada da questáo social, com oferta de respostas profissionais imediatistas e emergenciais. Esse cenário exige maior consciência crítica dos profissionais em relaçáo aos processos alienantes que atravessam o cotidiano do seu exercício profissional, tanto quanto a busca de estratégias para seu enfrentamento.

Com isso, as determinaçóes que estruturam a vida cotidiana, tal como colocadas por Heller (2016), tendem a se expressar fortemente no cotidiano do exercício profissional. A heterogeneidade hierárquica, traduzida na diversidade e aumento das demandas que precisam ser respondidas, muitas vezes leva os profissionais a selecionarem aquelas mais urgentes; o economicismo e o pragmatismo, expressos na necessidade de responder rapidamente a demandas e pressóes por produtividade; o reforço aos juízos provisórios e ultrageneralizadores, levando a um exercício profissional impregnado de analogias e mimese, com uma reproduçáo acrítica de açóes.

Não obstante, tais características não são conferidas apenas pelos profissionais, mas emergem de determinaçóes que, na maioria das vezes, estão fora do seu controle individual. Essas condiçóes sob as quais o trabalho de terapeutas ocupacionais ocorre contribuem para um exercício profissional pautado nas determinaçôes alienantes da vida cotidiana, em detrimento de uma prática que caminhe na direçâo da atividade humano-genérica, práxica, transformadora da realidade.

Indicamos, para exemplificar, alguns dos limites postos pela dinâmica do cotidiano para a concretização das açóes profissionais: o subfinanciamento das políticas, que acarreta no sucateamento dos equipamentos sociais por meio da insuficiência de recursos materiais e humanos; a retração de direitos e o afrouxamento dos vínculos trabalhistas; uma burocracia ${ }^{5}$ institucional parametrizada pela inação.

\footnotetext{
${ }^{4}$ Concepção de Estado baseada na perspectiva neodesenvolvimentista de que é possível mudar por dentro e negocialmente a privatização do Estado e ampliar sua intervenção pública mediante o fortalecimento de políticas sociais, supondo ainda estar em disputa as diretrizes das reformas neoliberais já consolidadas. Porém, para Castelo (2013, p. 122), o Estado social-liberal "muda apenas os aspectos do neoliberalismo para preservar sua essência [liberal]”; pois, apesar dos indicadores positivos colocados como resultantes do desempenho da economia, permanecem intactos os pilares que dão sustentaçáo à reproduçáo ampliada do capital.

${ }^{5}$ Trata-se de uma ferramenta racional para o atendimento das necessidades da administração de massa, pautando-se pela sujeição a normas e regras. Seu excesso, com o objetivo de responder mais imediatamente às demandas típicas das instituiçôes e políticas sociais
} 
Ora, se, de acordo com Heller (2016), é atividade humana consciente aquela capaz de se desprender da alienação da vida cotidiana em direção à genericidade, essas condiçôes sob as quais se dá o exercício profissional de terapeutas ocupacionais transformam em desafio o exercício de uma profissão que se intenciona práxis, tal como trazem Francisco (2001), Caníglia (1994) e Soares (1987). Para Francisco (2001, p. 66), a terapia ocupacional como práxis é aquela que:

[...] propóe o uso da atividade como recurso terapêutico, uma das possibilidades de ela vir a ser um espaço para transformar a si mesma e assim contribuir para a transformação social mais significante [...] através [de seu] fazer. Um fazer que busca conscientizar os [seres humanos] da opressão a que estão submetidos como membros de uma sociedade classista. Um fazer que desvela as determinaçóes sociais vividas, busca descobrir formas revolucionárias, mostra a contradição e o conflito da saúde numa sociedade de classes.

Caníglia (1994), adotando a concepção de práxis de Vázquez (2007), ao discutir a especificidade da profissão no conjunto das profissóes que atuam no setor da saúde, defende aquilo que ela denomina de saúde práxica como o objeto de intervenção de terapeutas ocupacionais, sugerindo, inclusive, que o nome mais adequado para a profissáo seria "Praxiterapia”. Já Soares (1987) utiliza o termo práxis unitária para se referir a uma prática terapêutico-ocupacional superadora das dicotomias e reducionismos, capaz de promover açôes transformadoras da realidade social.

Galheigo (2003), refletindo sobre as potencialidades da atuaçáo de terapeutas ocupacionais sobre o cotidiano, afirma que a profissão ocupa posição privilegiada e pode contribuir para a elaboraçáo crítica do cotidiano pelo sujeito. Para ela, "[...] o poder refletir a vida cotidiana e suas determinaçóes, esse olhar estrangeiro para o que parece rotina imutável, contribui de forma marcante para os movimentos de autodeterminação do sujeito, de reorganizaçáo do coletivo e ressignificação do cotidiano" (Galheigo, 2003, p. 108).

Percebe-se um horizonte, no exercício profissional de terapeutas ocupacionais, de construção de um fazer voltado para a transformação da realidade, sintonizado com a concepção de práxis defendida nesse texto. O constructo de cotidiano, em Agnes Heller (2016), adverte-nos que a transformação da realidade se dá mediada pela suspensão duradoura da cotidianidade em direção à atividade humano-genérica, alcançando a práxis. No entanto, Heller (2016, p. 48) afirma que não é possível realizar práxis e suspender o cotidiano permanentemente; porém, “[...] toda obra significativa volta à cotidianidade e seu efeito sobrevive na cotidianidade dos outros".

Nesse sentido, Guerra (2007) reforça a importância dos projetos profissionais críticos que, ao elucidarem seus compromissos éticos e políticos, parametrizam possibilidades de escolhas profissionais, estratégias e táticas, dentro dos limites da cotidianidade. Apesar de tais limites, os profissionais dispóem:

[...] de relativa autonomia em seu campo de trabalho, para realizar um trabalho social e complexo, saturado de conteúdos políticos e intelectuais e das competências teóricas e técnicas requeridas para formular propostas e negociar

neoliberais, contribui para o enquadramento do trabalho profissional, mediante a pressão para atingir metas de produtividade, transformando o trabalho social em um trabalho procedimentalizado e burocrático (Faermann \& Silva, 2015). 
com os contratantes institucionais, privados ou estatais, suas atribuiçóes e prerrogativas profissionais, os objetos sobre os quais recai sua atividade profissional e seus próprios direitos como trabalhadora/or assalariada/o (Raichelis, 2018, p. 37).

Defendemos, então, que, apesar das estruturas da cotidianidade atravessarem o exercício profissional, as políticas sociais e as dinâmicas institucionais, colocando limites ao trabalho enquanto ação que alcança o humano-genérico, é possível encontrar nessa mesma cotidianidade margens de movimento.

A condição profissional de terapeutas ocupacionais, caracterizada por uma base de conhecimento especializada que requer formação superior em longo prazo, constitui-se no que Larson (1980) denomina como barreira à alienação técnica, que dificulta a perda de controle profissional sobre a execuçáo da sua atividade, embora o trabalho assalariado imponha aos profissionais as alienaçóes econômica (sujeição formal ao empregador) e organizacional (sujeição aos critérios e normas burocráticas institucionais). Essa autora pontua que impor a alienação técnica aos profissionais implicaria que os empregadores tivessem o controle sobre o processo da atividade profissional por meio do domínio da expertise do profissional, o que, normalmente, não ocorre. Desse modo, os profissionais, embora subordinados às instituiçóes empregadoras, possuem suas autonomias técnica e ética, ambas resguardadas pelas leis de regulamentação e pelos códigos de ética profissionais.

Isso permite afirmar que há possibilidade de condução da vida, conforme definido por Heller (2016), no exercício profissional de terapeutas ocupacionais. Ou seja, apesar da impossibilidade da aboliçáo das estruturas alienantes da cotidianidade e de que a vida se torne desalienada o tempo todo, terapeutas ocupacionais podem se apropriar, "[...] a seu modo[,] da realidade e impor a ela a marca de sua personalidade” (Heller, 2016, p. 67). Afirmamos que essa marca pode se dar por meio da inseparabilidade das dimensóes técnica, ética e política do exercício profissional, em articulação com projetos societários que façam avançar a luta dos trabalhadores em geral.

A ênfase nessas dimensôes, como condição para uma prática profissional que possa suspender a cotidianidade e transformar vidas e realidades, decorre do reconhecimento de que o desenvolvimento científico e tecnológico, proporcionado pela sociedade contemporânea, eliminou as barreiras técnicas para resolver inúmeros problemas (pobreza, fome, desemprego, falta de moradia etc.) que afligem os sujeitos que demandam o trabalho de terapeutas ocupacionais. Conforme afirma Nosella (2008), existindo as condiçóes técnicas para solucionar diversos problemas da humanidade, resolvê-los passa a ser uma escolha, um dever ético, uma opção política.

Ainda sobre o compromisso ético-político na terapia ocupacional, Galheigo (2016, p. 65) coloca que é:

Um compromisso ético, por intervir no plano da vida, em seus movimentos de resistência e afirmação; um compromisso político, pela contínua explicitação dos jogos de forças macro e micropolíticos existentes, pela defesa da autonomia, da cidadania e do direito e pela busca de novas estratégias de construção e/ou fortalecimento dos coletivos. 


\section{Consideraçóes Finais}

O cotidiano e a cotidianidade têm se tornado temas de discussão, reflexão e pesquisa da terapia ocupacional nas últimas décadas, ocupando lugar privilegiado enquanto locus de intervençáo, buscando a transformação da realidade das populaçôes acompanhadas, tendo como centralidade o cotidiano do outro. Neste ensaio, realizamos um deslocamento reflexivo, com base no pensamento de Agnes Heller, colocando como foco da discussão o cotidiano do exercício profissional, também atravessado pelas estruturas da cotidianidade (heterogeneidade hierárquica, espontaneidade, pragmatismo, economicismo, ultrageneralização e mimetismo) que lhe estabelecem limites.

Apesar da tendência à alienação do cotidiano, defendemos também que é possível a suspensão temporária da cotidianidade no exercício profissional em direção ao humanogenérico, possibilitando açôes terapêutico-ocupacionais como ação práxica, pois:

A homogeneização é um movimento do "eu" para o "nós", em que homens e mulheres se tornam representantes do gênero humano (Heller, 2016). Isso nos leva à reflexão da importância desse processo em tempos atuais de extrema individualizaçáo, seja em relação a valores humanos ou pelo modo como decodificamos as necessidades das pessoas com as quais lidamos. Parece ser correto afirmar que um meio para superar esse individualismo está na compreensão de que a prática profissional pode ser um dos caminhos para alguma suspensão da alienação cotidiana.

Para isso, consideramos a necessidade de articular as dimensões técnica, ética e política do exercício profissional, transitar entre as esferas individual e coletiva na leitura e intervenção sobre as demandas profissionais, superar a dicotomia teoria e prática, além de reafirmar o compromisso com a transformação da sociedade, em que lutas por redistribuição e reconhecimento produzam justiça e participação social (Fraser, 2004).

Ainda, terapeutas ocupacionais não podem circunscrever a sua prática aos limites institucionais, limitando-a ao atendimento das demandas imediatas e emergenciais. Parece-nos necessário construir parcerias com demais trabalhadores na perspectiva de enfrentamento aos processos neoliberais de precarização e alienação do trabalho, fomentando a organização coletiva; ressignificar as solicitaçóes institucionais, revertendo a lógica de respostas acríticas e não se conformar aos moldes do produtivismo institucional e das demandas apenas burocráticas, o que envolve a leitura crítica sobre as relaçóes institucionais e sobre os processos de trabalho nos contextos em que se insere, dentre outras estratégias encontradas nas particularidade de cada espaço de trabalho. Não obstante, é importante que possuam clareza da intencionalidade das suas açóes, alinhando seus projetos profissionais a projetos societários intencionados e direcionados à transformação necessária do status quo.

\section{Referências}

Bezerra, W. C. (2011). A terapia ocupacional na sociedade capitalista e sua inserção profissional nas politicas sociais no Brasil (Dissertação de mestrado). Universidade Federal de Alagoas, Maceió.

Borges, A. M. C. (2015). O mercado de trabalho nos serviços sociais. O Social em Questão, (34), 87-106.

Caníglia, M. (1994). Terapia ocupacional: objeto e metodologia. Belo Horizonte: Expressa Artes Gráficas.

Carvalho, M. C. B. (2011). O conhecimento da vida cotidiana: base necessária à prática social. In J. P. Netto \& M. C. B. Carvalho (Eds.), Cotidiano: conhecimento e critica (pp. 13-63). São Paulo: Cortez.

Castelo, R. (2013). O canto da sereia: social-liberalismo, novo desenvolvimentismo e supremacia burguesa no capitalismo dependente brasileiro. Em Pauta, 11(31), 119-138.

Faermann, L., \& Silva, F. C. (2015). As implicaçóes da burocracia na sociedade e seus rebatimentos no serviço social. UNITAU, 8(2), 51-59. 
Francisco, B. R. (2001). Terapia ocupacional. Campinas: Papirus.

Fraser, N. (2004). Repensando a questão do reconhecimento: superar a substituição e a reificação na política cultural. In C. A. Baldi (Ed.), Direitos humanos na sociedade cosmopolita (R. C. Costa, Trad., pp. 601621). Rio de Janeiro: Renovar.

Galheigo, S. M. (2003). O cotidiano na terapia ocupacional: cultura, subjetividade e contexto históricosocial. Revista de Terapia Ocupacional da Universidade de São Paulo, 14(3), 104-109. http://dx.doi.org/10.11606/issn.2238-6149.v14i3p104-109.

Galheigo, S. M. (2016). Terapia ocupacional social: uma síntese histórica acerca da constituição de um campo de saber e de prática. In R. E. Lopes \& A. P. S. Malfitano (Eds.), Terapia ocupacional social: desenhos teóricos e contornos práticos (pp. 49-68). São Carlos: EdUFSCar.

Galheigo, S. M. (2020). Terapia ocupacional, cotidiano e a tessitura da vida: aportes teórico-conceituais para a construção de perspectivas críticas e emancipatórias. Cadernos Brasileiros de Terapia Ocupacional, 28(1), 5-25. http://dx.doi.org/10.4322/2526-8910.ctoAO2590.

Galheigo, S. M., Braga, C. P., Arthur, M. A., \& Matsuo, C. M. (2018). Produçáo de conhecimento, perspectivas e referências teórico-práticas na terapia ocupacional brasileira: marcos e tendências em uma linha do tempo. Cadernos Brasileiros de Terapia Ocupacional, 26(4), 723-738. http://dx.doi.org/10.4322/2526-8910.ctoAO1773.

Guerra, Y. (2007). O projeto profissional crítico: estratégia de enfrentamento das condiçóes contemporâneas da prática profissional. Serviço Social \& Sociedade, 28(91), 5-33.

Guerra, Y. (2016). Transformaçóes societárias, Serviço Social e cultura profissional: mediaçóes sóciohistóricas e ético-políticas. In E. Mota \& A. Amaral (Eds.), Cenários, contradiçōes e pelejas do Serviço Social brasileiro (pp. 83-110). São Paulo: Cortez.

Heller, A. (1987). Sociología de la vida cotidiana. Barcelona: Ediciones Peníncula.

Heller, A. (2016). O cotidiano e a história. São Paulo: Paz e Terra.

Larson, M. S. (1980). Professionalization and educated labour. Theory and Society, 9(1), 131-175. http://dx.doi.org/10.1007/BF00158895.

Lopes, R. (2016). Cidadania, direitos e terapia ocupacional. In R. E. Lopes \& A. P. S. Malfitano (Eds.), Terapia ocupacional social: desenhos teóricos e contornos práticos (pp. 29-48). São Carlos: EdUFSCar.

Lopes, R. E. (1991). A formação do terapeuta ocupacional: o currículo: histórico e propostas alternativas (Dissertação de mestrado). Universidade Federal de São Carlos, São Carlos.

Nosella, P. (2008). Ética e pesquisa. Educação \& Sociedade, 29(102), 255-273. http://dx.doi.org/10.1590/S010173302008000100013.

Patto, M. H. S. (1993). O conceito de cotidianidade em Agnes Heller e a pesquisa em educação. Perspectivas: Revista de Ciências Sociais, 16, 119-141.

Raichelis, R. (2018). Serviço Social: trabalho e profissão na trama do capitalismo contemporâneo. In R. Raichelis, D. Vicente \& V. Albuquerque (Eds.), A nova morfologia do trabalho no Serviço Social (pp. 25-65). Sáo Paulo: Cortez.

Salles, M. M., \& Matsukura, T. S. (2015). Estudo de revisão sistemática sobre o uso do conceito de cotidiano no campo da terapia ocupacional na literatura de língua inglesa. Cadernos de Terapia Ocupacional da UFSCar, 23(1), 197-210. http://dx.doi.org/10.4322/0104-4931.ctoARL510.

Soares, L. B. (1987). Terapia ocupacional: lógica do capital ou do trabalho? Retrospectiva histórica da profissáo no Estado brasileiro de 1950 a 1980 (Dissertação de mestrado). Universidade Federal de São Carlos, São Carlos.

Vázquez, A. S. (2007). Filosofia da práxis. São Paulo: Expressão Popular.

\section{Contribuiçáo dos Autores}

As reflexóes deste texto decorrem do trabalho final entregue por Waldez Cavalcante Bezerra e Ana Carolina de Souza Basso na disciplina "Referenciais Teórico-metodológicos em Terapia Ocupacional”, do Programa de Pós-Graduação em Terapia Ocupacional da UFSCar, sendo eles responsáveis pela concepção do trabalho e redação do texto. Roseli 
Esquerdo Lopes colaborou com a discussão, revisão e redação final do texto. Todos os autores aprovaram a versão final do texto.

\section{Autor para correspondência}

Ana Carolina de Souza Basso

e-mail: ana.basso@ifrj.edu.br

\section{Editora de seçáo}

Profa. Dra. Marcia Maria Pires Camargo Novelli 